ISSN: 2162-3104 Print/ ISSN: 2166-3750 Online

Volume 6, Issue 1 (2016), pp. 216-240

(C) Journal of International Students

http://jistudents.org/

\title{
Student to Scholar: \\ Learning Experiences of International Students
}

\author{
Yolanda Michelle Palmer \\ University of Saskatchewan (Canada)
}

\begin{abstract}
The author discusses the learning experiences and processes of selected international graduate students within a Canadian university as they progressed from student to scholar. Inspired by social learning theorists Lave and Wenger's (1991) notion of apprentice to masters in situated learning and communities of practice, the student to scholar framework sheds new light on the phenomenon of being an international graduate student. The arguments within the paper counter traditional views of learning as occurring solely through classroom engagements and offers that international graduate students learn and achieve "scholar" status through situated practice, professor mentoring and triple learning. Data were captured through observations and in-depth phenomenological and semistructured interviews.
\end{abstract}

Keywords: International Students, Academic Language and Literacy, Triple Learning

In recent times, and with many possibilities for academic advancement and immigration after graduation, Canada has become a leading destination for international students in pursuit of their academic and professional goals (Association of Universities and Colleges of Canada [AUCC], 2011; Bhandari \& Blumenthal, 2011; Choudaha \& Chang, 2012; Citizenship and Immigration Canada [CIC], 2012; McHale, 2011). When contemplating study opportunities, Canada's affordable education also propels the growth in the number of students seeking to study within the country. According to the Canadian Bureau for International Education [CBIE], in 2012 Canada was ranked the world's seventh most popular destination for international 
students (CBIE, 2014). In the same year, there was a marked increase in the numbers of international students entering the country. CBIE also reported that the year 2012 saw a 94\% increase in the number of international students enrolled in Canadian post-secondary institutions as compared to 2001 figures (136, 000 in 2001 to 265,000 in 2012).

According to Florida, international graduate students are distinct and belong to the so-called "creative class" (2002). These individuals form a "key part of building a stronger international and intercultural scope to pedagogy and research and are crucial to Canadian campuses" (Cudmore, 2005, p. 47). The AUCC (2014) also contended that international students represent approximately $20 \%$ of the total full-time graduate students in Canadian post-secondary institutions. According to AUCC (2014), when Canadian classrooms and labs are enriched by people and ideas from around the world, all students benefit. Not only do international students broaden local perspectives, but they also help to create mutually beneficial economic, diplomatic, and cultural ties, as their presence transforms classrooms into a cornucopia of identities, ideas, skills and competencies.

Given the growing numbers of international graduate students entering Canadian post-secondary institutions from diverse backgrounds, how do these individuals come to terms with and successfully negotiate their personal learning experiences and academic pursuits overseas? Among the plethora of literature regarding international students, few studies chronicle the learning experiences of Canadian international graduate students. Also notably absent from the literature are deliberations directly related to the lived learning experiences of international students. Even less visible are documented explorations of graduate students and how they are able to advance from student to scholar when studying in Canadian universities. Due to the dearth of qualitative documentation within the Canadian higher education landscape, Canadian scholars and researchers tend to draw on research from international counterparts such as the US, UK, New Zealand and Australia. Studies into the experiences of international students, however, often highlight such students as encountering myriad sociocultural and academic issues and stresses as they attempt to adjust to their new learning environment (Abel, 2002; Bamford, 2008; Fiske \& Lee 2012; Fu, 2013; Gebhard, 2010; Grahame \& Poyrali, 2007; Gunawardena \& Wilson, 2012; Lacina, 2002; Leary, 2011; Maguire, 2011; Madden-Dent, 2014; Morgan, 2012; Popadiuk \& Arthur, 2004; Sullivan \& KashubeckWest, 2015; Tannis, 2010; Zhang, 2011).

An understanding of the learning experiences of foreign graduate students and the approaches they take to achieve academic success is a necessary tool for university personnel, faculty, policy makers, and prospective and current international students. Having knowledge of the 
learning practices will allow for more efficient pedagogy and could largely improve the levels of success and retention of students as they strive toward their academic pursuits. Social learning theorists Lave and Wenger's (1991) theory of learning offers a model that is useful in understanding the learning practices of international graduate students. They contended that learning is socially situated, authentic and is "clearly related to the real world" as individuals see relevant processes at work and replicate them (Gibbons 2009, p. 34).

Notably, graduate students from overseas enter post-secondary institutions already enculturated in varying disciplines, cultures and backgrounds. Upon entering their institutions of choice, these students, in many instances, come to realize that the cultural capital with which they enter differs from that of the host academy (Bourdieu, 1986). Their customs, traditions, experiences, accomplishments, skills, values, identities, and languages, among other competencies, highlight the differences and cultural diversity in the new environment (Maguire, 2011; Mamiseishivili, 2011). Many are established scholars in their own right and have matured into a unique identity with an established sense of being in a particular society. Thus, entering into and negotiating the landscape of the new learning community or environment can prove challenging and even exciting (Leary, 2011).

The cultural and academic differences with which these students enter programs of study overseas require students to shift and refocus their lenses from the familiar frames of home to the new frames of the host country and institution. This shift often causes misunderstandings between international students and faculty on both academic and personal levels. Trice (2003) contended that faculty members and host students often do not adequately understand and appreciate the personal needs and experiences of international graduate students. The lack of understanding of the experiences of international students facilitates misconceptions and assumptions that international students are plagued with issues. Thus, students are often negatively perceived and forced to fit within a prescribed mold by colleges and universities (Trice, 2003). Because of their lack of knowledge and understanding of the academic culture and rhetoric in North American academic institutions, international students are often perceived as problem-oriented and needy (Tran, 2013), and sometimes projected as "supplicants, strangers, outsiders, sojourners, social isolates and people living in learning or linguistic deficit” (Margison, 2013, p. 9). Additionally, they are sometimes thought to be "insufficiently adjusted to higher education in their host country academically" (Rienties, Beausaert, Grohnert, Niemantsverdriet \& Komers, 2011, p. 1) by professors and university personnel. 
CBIE (2009), Leary (2011) and Maguire (2011) confirmed the lack of understanding of the learning experiences of international students in Canada and urged that more research needs to be done in this area (CBIE, 2009). Later, echoing the call for more investigation into the lived learning experiences of international graduate students, Maguire (2011) reasoned that studies into the experiences and learning practices of international students are important for all stakeholders in higher education. She reiterated the lack of such studies and urged that such studies be encouraged and documented. This information, she maintained, is relevant in assisting professors and students themselves to understand the otherwise-thought homogeneous experience of being an international graduate student (M. Maguire, personal communication, February 2, 2015). Thus, the following research question is addressed in this article: How do international graduate students learn and become scholars in Canadian post-secondary institutions?

\section{THEORETICAL BACKGROUND}

The possible experiences that international graduate students encounter in a new academic environment are largely shaped by the psychological tools (Vygotsky, 1988) and capital (Bourdieu, 1986) with which they enter their overseas education. These include gestures, language, sign systems, behavioral patterns, and decision-making systems that are largely identifiable by and rooted in the cultures from their countries of origin. Bourdieu (1986) envisioned and argued that education is central to the construction and diffusion of social, linguistic and cultural capital. Bourdieu and Passeron (1990) maintained that students without the social and cultural capital of the dominant group are disadvantaged from the outset. They argued that students who had the social and cultural capital of the dominant culture were more likely to succeed in learning institutions. This probability is heightened since the forms of knowledge of the privileged are valued over those of the "newcomers" (Egbo, 2008). Therefore, in order to become successful scholars, international graduate students would have to gain the relevant social, cultural and linguistic capital that affords them full membership into the new academic community.

The terms "student" and "scholar," have long been used interchangeably. A closer study of the two reveals that a student is one who is under the tutelage of a teacher or an instructor, whereas a scholar is considered an expert in a given field (Freedictionary.com). Implicit in these definitions are the notions of dependence and independence. Students are often considered to be dependent on their teachers or advisors, while 
scholars are viewed as functioning and learning independently of such agents. Students are viewed as dependent because they often do not initially possess the cultural, linguistic, and academic capital of the new academic group they seek to join that would allow them to meet the academic expectations befitting that of a scholar. Acquiring the capital to act independently within their scope of academic practice, then, is a rite on the way to becoming a scholar for international students. Given that the cultures and the teaching learning practices from which international students come often differ from those of host universities, how are they able to achieve the move from students to scholars, or full members of the academic community?

According to Lave and Wenger (1991), newcomers learn how to become full members of a community of practice through legitimate peripheral performance (LPP). This implies that learners perform peripheral, yet productive, tasks that contribute to the goals of the academic community and build their identities through their discussions or class presentations. Through LPP, students are able to learn the acceptable academic protocols and move from being students and novices to scholars and experts. These protocols include norms and behaviors of the new community and college or university. These are not typically formally taught. Instead, they are learned vicariously as students watch and listen attentively to established scholars, their professors, and other students then respond, act and participate in the community. So then, a "person's intentions to learn are engaged and the meaning of learning is configured through the process of becoming a full participant in a sociocultural practice” (Lave \& Wenger, 1991, p. 29). In becoming a full participant, the student then shifts into the position of a scholar.

Wenger (1998), furthermore, maintained that learning is socially undergirded and happens through socially contextualized situations in communities of practice. He offered a more comprehensive theoretical description of learning as a process of participation situated in a community of practice. Wenger argued that situated learning/practice is integral to the lived experience of human beings. This inescapable notion of learning countered the general notion that learning is organized through curriculum and classroom activities only and has a start and an end; and that students are blank slates or "depositories" (Freire, 2000) into which knowledge is deposited. Learning, then, is contextualized, real to life and ongoing. In outlining a theory of social learning, Wenger (1998) made a case that for learning requires these elements: a community, an experience, practice and changed identity. He emphasized and maintained that learning occurs through situated practice. 
In situated practice, learning happens through doing and actively engaging socially with the academic community of practice "in the context of their lived experiences" (Wenger, 1998, p. 3). In the case of new graduate students, they have the opportunity of doing, undoing and redoing as they act and cooperate with masters in the field. This positions learning as ongoing and transformational as newcomers operate within the academy and encounter new activities that will undoubtedly teach them useful skills that will assist them on their trajectory through the academic community. As the newcomers engage these social activities and co-participate, their identities gradually transform. Learning then, implies "becoming a different person” (Lave \& Wenger, 1991, p. 53).

\section{RESEARCH METHOD}

The research uses phenomenology and hermeneutics in terms of its conception, design and methods. Phenomenology allowed for the exploration of the day to day lived experiences of participants as students (van Manen, 1997). Through hermeneutics the researcher was able to understand and interpret the experiences of participants (Gadamer, 2004). Six international graduate students between the ages of 25 and 35 volunteered to participate in this study. Participants at the time of the study were fulltime students at a western Canadian university and were studying in one of five colleges and departments. These individuals held degrees from their home countries prior to entering their programs of study in the university. Additionally, each had already completed at least one year of full time study at the university and in all cases this was their first interaction with an overseas post-secondary institution. Completion of at least one year of full-time study was an important criterion; participants were required to reflect on and recall past academic experiences within the university. In order to maintain confidentiality and anonymity participants were assigned pseudonyms.

The intent of this study was to explore the multi-layered and complex depth (rather than the breadth) of the phenomenon of becoming scholars. The researcher's aim was to extricate the learning patterns of these students at the university through the flow of their experiences, hence the limited number of participants. Using fewer participants allowed the researcher to engage each participant more intimately. Furthermore, the sample selected is representational and does not seek to offer generalizations for full scale practice.

The data collection processes within this study included ethnographic observations and in-depth phenomenological interviews about 
their daily lived experiences within the academic community of practice. Data were collected over two academic terms (approximately 8 months). At the beginning of each term participants were interviewed. Interviews lasted from 60 to 90 minutes. Participants were also observed over a two-day period as they went about their daily academic tasks. Observation data were strengthened by follow-up conversations between the researcher and participants. These follow-up conversations were used to clarify observed behaviors. To close the data collection process, participants were again interviewed at the end of the second term. Interviews were transcribed verbatim and put through a process of member checking. Member checking gave participants the opportunity to verify, clarify, edit, add/or delete data. Analysis of the data was inductive and iterative as transcribed data, observation notes and researcher journal and notes were analyzed through rigorous multiple readings and immersion approach as the researcher recursively read back and forth between the transcripts, notes and literature. Data were coded and recoded individually and comparatively until themes that fit the individual and combined stories emerged (Polkinghorne, 2005).

The study had certain imposed boundaries, parameters and situations. These limitations may have impacted the research and findings and consequently limit their use in describing the learning practices of international graduate students generally. Firstly, the study was conducted at a single Canadian post-secondary institution. Thus, the stories and perceptions presented reflected only those of international students attending that university. Secondly, only international graduate students were enrolled as participants in the study. The stories of international undergraduate students were not represented. Thirdly, international graduate students with prior international study experience were not qualified to participate in the study. Thus, participants selected did not necessarily represent the overall demographics of international graduate students at the university. Lastly, the study was based on the participants' perceptions and perspectives.

\section{FINDINGS}

The basis of this article is to describe the learning practices of selected international graduate students as they progress from student to scholar. This process situates participants along a continuum on which they progress from being dependent students to becoming independent scholars within the university, thereby gaining membership and access to the academic community. Through participants stories it was concluded that they were able to make the transformation from student to scholar through situated learning, mentorship and triple learning. 


\section{Learning through Situated Practice}

Analysis of the collected stories led to the conclusion that participants were able to achieve a composite of the generic, transferrable skills that are required of and developed by academic study and research through situated learning. Participants in the study-although limited by their cultures and lack of capital—were able to participate in the "trade" of learning through their observations and participation in everyday activities in the academic community of practice. As an example, one participant expressed,

My last assignment with a research course, the professor told me I had big problems in my literature review part because she pointed out two problems. The first one is I did not have my own thought in my literature review I just wrote down what happened, I just put what they wrote in the literature. I did not put in my own thoughts inside. That is a big problem. The second one is when I cite literatures... the form is not right. It made me look like I had plagiarized. She said I need to make some changes. She also pointed out a lot of citing forms, you know, incorrect forms here and there in my assignment. That was my last paper and at first I felt so upset and shocked because before when I tried to finish this last paper I spent two or three weeks on this, finding literatures and reading those, but the results turned out to be like this! I felt so frustrated. I felt I am a loser or something like that, you know you feel, and I feel I made so much effort on doing this but the professor still was not satisfied. (Rueda, Master's student)

Rueda's statements echoed the thoughts of the other international graduate students who participated in the present study. Through having to redo assigned writing tasks, she learned the protocols of academic writing. While there were no explicit attempts at teaching the rhetoric and academic protocols for writing her paper, Rueda soon realized that this was an expectation of higher education. She acknowledged that in her home culture the concept of plagiarism did not exist. She bore shame as she sought to acknowledge her error and move forward. Over time, she found that through rewriting her paper she gained valuable academic literacy that would help her in her shift from student to scholar. Other participants also spoke of their 'missed opportunities' or what some would have deemed a failure in assigned tasks. Viewing the students' experience through the lens of situated learning it can be understood that while these participants were engaged in redoing their academic tasks, learning was occurring. The act of these individuals writing and rewriting papers and examinations, sometimes 
independently, gave them the opportunity to grasp the appropriate and desired protocols within the new contexts of their departments, colleges and university.

Interestingly, participants demonstrated that at some point in the process they recognized their peripheral status in the environment, or being on the edge of the academic community, and needed to take actions to 'fend for themselves' if they were to grow in scholarship. After recognizing their outsider status and bearing in mind their intended goal of becoming scholars, each critically assessed his or her situation and reached inward to find strength and resolve, through his or her own agency, to overcome these challenges. Egbo (2008) regarded critical reflection as the most significant element of praxis. He, further, described praxis as the process through which the individual assesses him or herself critically through a series of deep probes surrounding the personal histories, beliefs of the individual, and how these affect their journeys as overseas students. When individuals are able to identify who they are, they are able to "unleash their personal power, an internal force" (Egbo, 2008, p. 127) that enables them to recognize the inner strength that they possess. They then are able to effect positive changes in their own lives. This inner strength is their resilience or the ability to overcome. For instance, Maria, a Master's student stated, "I realized that I was here by myself and needed to find a way to deal with the issue."

These utterances were echoed by Kuri, a Master's student. She, however, added that she managed to become better through her daily activities and conferencing with peers and professors, who might have had similar experiences. In the case of Rueda, she took responsibility for her failed attempt and sought help in addressing her academic malaise.

I did not know what to do until I found a friend to give me some help, you know, some writing tips. I also have to thank my husband who also helped me a lot correcting my papers. Then I spent like a whole week rewriting my paper. I submitted my paper again and this time the professor was satisfied.

The engagement of Kuri, Rueda and other participants in the study mirrored Lave and Wenger's (1991) belief that people initially join communities and learn from the periphery of the class. This learning, according to Lave and Wenger, occurred as participants were engaged in real life situations. Through doing and redoing, participants were able to grasp appropriate academic protocols that allowed them to grow in competence in their academic activities. As they became more competent, they became more involved in the main processes of a particular community; that is, watching and listening to others. From this they were able to move from legitimate 
peripheral participation to "full participation" (Lave \& Wenger 1991, p. 37). Learning, thus, is not seen as the acquisition of knowledge by individuals; rather it can be viewed as a process of social participation. Learning is ubiquitous in ongoing daily activities (Lave \& Wenger, 1991) and the nature of the situation impacts significantly on the process.

Kuri described her challenges and how, through observation and modelling through doing, she learned valuable behaviors and skills that were useful to achieving her academic pursuits.

I must say the first four months it was difficult for me to get to class on time. I do not know why, I was always late. But then what happened once I moved to campus apartments I then observed what other students were doing. I observed that they were packing their lunches the night before. I observed that they did their laundry on Friday. I observed they were doing their groceries on Saturdays. That is when I noticed how the other students are living a disciplined life. When did they cook? They all cooked only on the weekends. They do not cook every day. I noticed at the apartment that all the other students they used to cook only on the weekends. They used to make their gravies, their sauces and they used to freeze it up for the whole week. That is when I noticed that wow that is a great thing. In the morning they used to just pick up their lunch. So, I felt that was so good! I mean, and in the morning, they used to keep, from the night before, like what they are going to wear the next day to school handy. And, you know, you learn if you are staying with students. Then I realized, like these guys how do they chill? How do they relax?

I noticed what my other roommates used to do. They would pack up their lunch the night before because at the apartment on campus there was one common fridge. So I realized that my friends use to pack up their lunch a night before. They used to, what they were going to wear the next day; they used to keep it ready. For winter they used cleats, which is a great thing I learnt. So you learn these things from people who are on the same level as you are. (Kuri, Master’s Student)

Another participant described how her presentation methods and written tasks were initially dissimilar to the local host students until she adapted to her new environment. She explained that when she observed her classmates and their presentations "they seemed fearless and confident:" 
The Canadian students are very confident when they are presenting. Even when they do not know their stuff they are very confident about it. The way they talk, make eye contact, they are very free. My first presentation was a total nightmare. It was in our research methods class. We had to present our proposal. We were to give an idea of our research since it was evolving we probably did not know exactly what we were going to do. It was just to give the class an idea of what we wanted to do. Our supervisor was supposed to come in and sit in the class. My goodness! I could not speak. I was just a nightmare. It was the first time I was doing a presentation in front of a group. We were like ten people. I just felt like the ground would just break. I kept reading from the screen. I was not making enough eye contact (Maria, Master’s Student)

Through her observations she decided that she would emulate these patterns, thus her presentations improved, and in time she became engaged in multiple tasks, making approximations and eventually learning the ways of academic literacy fostered in the university. Lave and Wenger's theory on learning also alluded that learning is an ongoing process as students do and redo activities until they have a grasp of the process. Therefore, all participants were growing in the community of practice, since each related anecdotes about doing their scholarly tasks and achieving levels of success.

\section{Learning through Professor Mentoring}

The "scholars to be" presented in this study also highlighted the relevance of mentorship. Each student identified being mentored by another as a way of the university. When they spoke about the differences in professor-student relationship, it was concluded that this was indeed mentorship. Unlike their previous studentship in their home countries, professors in this university were approachable and sought to assist students with adaptation strategies in the new academic environment. Garcia, Maria, and Rueda spoke about being invited to the homes of their professors. They found this to be uncharacteristic of their previous experiences with professors. Rueda described her experience,

I would definitely say Chinese professors, at least according to my own experiences are not as encouraging as the professors here. [F]or most Canadian professor I don't know why they thought I was always working very hard. They always tell me don't work so hard enjoy your life or whatever. (Rueda, Master's student) 
In the case of Maria, who came from an education system steeped in "power struggles" where there was an obvious gap between students and professors, she became alarmed at the relationship patterns that existed between students and professors in the university. She had never witnessed or experienced a student referring to a professor by his or her first name in her home country. In her previous studies, students who did not address professors by the title "Dr." were often deemed impolite and thought to lack moral and ethical standards. She related:

The professor-student relationship here was kind of shocking to me. I remember when I was corresponding with my professor I was addressing him as "Dr." at a point he corrected me. Then I came and I had a co-supervisor who wanted me to just call him by his first name. I had to tell him that I was uncomfortable calling him by his first name. He insisted that I call him by his first name. It was hard but I kept at it and tried greeting him that way whenever we met. Eventually I got used to that.

Our system is different. There is a lot of power struggle. People want to feel very important so... I mean if you have a Ph.D. it is like you have achieved. That is the highest achievement that you could ever have. There is always that gap between students and professors.

If I were to compare with this place you can see the difference. Here you are free to talk to your professors. I forgot to mention the fact that [back home] we like titles a lot so you have to address them by the professional titles. You dare not mention their first names without adding their titles that would just cause a lot of problems. That is viewed as a big disrespect so you do not dare to do that. I think it is more about power. I find it is like they want to feel on top and belittle students. They do not see the need to draw students closer and allowing them to learn from them.

These relationships with faculty countered students' previous experiences of the professor-student relationship. For these participants, relationships with professors positioned students as having significance and helped students integrate into the group as 'scholars to be' and 'faculty in waiting.' These relationships were novel for the participants in that students felt they were able to have valid contacts and conversations with their professors or mentors. These conversations helped to put their minds at ease and gave them a comfort level through which they could dedicate more effort to their studies. Rueda sanctioned this view when she shared her experience of visiting with a professor. 
I experienced, I think, different kinds of professors in Canada and think it is the happiest experience in Canada. The general features are they are: very nice, helpful, respectful, and they like to have interactions after class even in daily life, you know. Like we go to a professor's home to have potluck and we can drink beer or have some very nice chat in a restaurant or something like that. Yes, I think that I even have more connections with Canadian professors than with local students. I did not expect that before. I do not know why. Maybe professors are more open, more patient to hear about your story or your country, your culture because not every local student is willing to hear you talk about your country, your culture or how you feel about what, what and blah, blah. They just try to, you know young people, like to talk about those things they are interested in not what you are interested in. but to professors they always like to hear about your voice. I think that may be because of their occupation, they are professors. They always like to listen so I feel even more interaction with professor. Professors here are more encouraging. They want you to be more active in class.

These experiences of professor-student relationships reiterated the need for belonging and relationships. Also, evident is the power of these relationships and how they enable students to become better versions of themselves. Essentially, through their relationships with professors these international graduate students felt valued and important to the processes of learning and culture with their colleges and departments. Having this sense of belonging enabled them to view themselves as important thereby motivating them to engage more fully in their studies, leading to successful completion.

\section{Learning within learning}

Through their stories, participants further described a path of negotiating among three cultures and sub-cultures and registers of English: home, provincial and academic. Fluent in their home language, these students came to live in the social realms of the local environment. The local provincial English heard in everyday speech in the new local community is not the same as the academic language they are expected to master as they progress to scholar identity. Academic language is largely discipline-based and tends to be restrictive and more formal than the informal, social language used in their home communities or in the local host community. Academic language is complex and specialized. Its 
complexity arises from the fact that each discipline uses variations or subregisters of English.

The idea of a linguistic variance was highlighted in the stories of all participants as they expressed challenges with the Englishes used within their new communities of practice. In addition, these students also had to negotiate English registers through or against the backdrop of their native language, which they used to buffer the agitation they felt while switching and negotiating appropriate communicative patterns in their new academic and linguistic communities. Owaja, Georgie, and Rueda who were nonnative English speakers (NNES) from China. These students studied English as an additional language (EAL). They expressed sentiments that the language used in the academy was different from what they had learned from the language books used in their home country. They shared their story of a visit to a friend who tried to share a joke about an athlete "going to the bar.”

I remember once he [Georgie's friend] told us a joke. He said, "You went to a bar, ouch!" He went to a bar ouch! Why? What is the point? What is that? I just felt so puzzled. You went to a bar ouch? He saw us so puzzled and that we do not understand so he felt a little bit disappointed or he tried to cheer us up but the result turned out to be like this; we do not understand... Then he explained to us like bar as two meanings. One is, you know, a pub another is something like a stick. So "you went to a bar, ouch!” I did not understand until he explained to us. He tried, you know, to improve communication, to improve the relationship but we do not understand. There are language problems sometimes he tell us some jokes but I do not know the words or I do not understand what the point of laughing. Why do you laugh? I do not understand, so you feel you are left out sometimes. They are talking about these movies, band, music and we do not understand, we do not know them you also feel left out. (Rueda, Master's student)

These international students were familiar with "going to the bar," as visiting a place where friends hang out and have a drink. They were unaccustomed to the word being used in its form as "a counter or long rod" (Oxforddictionaries.com) Their friend's use of the word with the latter meaning threw them into confusion. Georgie added,

In China, the way we learned greeting in China, like we learned "hello" or we say "how do you do?" What we learned in China is that when you first meet someone say "how do you do?" For the 
second time around or for your friends you can say "nice to meet you." Or for the first time you can say "nice meeting you" and then the second time or after that you can say "nice to meet you." But here no one pays attention to that. No one is saying "nice meeting you." Here everyone is like" hey, what is up?" or "hey, how is it going?" No one says "how are you?" like we learned in China, but everyone says "how are you doing?" instead. We did not know what "how are you doing" means the first time we heard. I asked my wife and my younger sister " do you know what is how are you doing? They both responded "no", they do not know. (Georgie, Ph.D. Student)

All participants shared stories of their struggles with the home, local provincial and academic |Englishes. They contended that the three were distinct and they had to learn, and determined which register was appropriate in which context. Owaja pointed out that "what we learned about the English language is different from the English spoken here [at the university], especially in speaking and listening.” Georgie and Rueda spoke of the varied registers of English. They spoke of their negotiations among the 'forms' of English they learned in China, the English used by the locals in Canada, and the marked differences from the academic or higher register of English they needed to employ at the university. Garcia, whose first language is English, expressed that her experience was that the language and vocabulary she used were not readily accepted by the university.

I was surprised that there were some words that I knew to be scholarly and have been using for years in the Caribbean and were accepted as scholarly, there were not recognized here and so they were considered incorrect or inappropriate. Words like postulate, posit, purport were not used in the North American setting and I knew these to be legitimate words. (Garcia, Ph.D. student)

These differences caused much anxiety and stress for individual participants who struggled to acquire the academic language required for participation in classes. Owaja, for example, was mostly perturbed by the speed of speech of locals and faculty. He was bothered by the fact he could not always "catch" the speed and full understanding of what was being said to him. He also confessed that he did not always know the appropriate response. Hence, he was often confused. He said,

I learned English for maybe ten or eight years in China and I also learned English as a major in university so my English, I think, is 
above average level in Chinese student but I still face a lot of problems, you know, communication problems when I try to communicate with some of my English speaking friends. You can just talk some kind of superficial, not deep, you know. But if you speak in Mandarin or Chinese we can speak a lot broader, a lot deeper and yes. You know, in English when you try to say something and you are stuck and you have to find the words, what that word is? Sometimes, you know sometimes your language problem makes your communication less powerful, less impressive. (Owaja, Master’s student)

Not knowing the appropriate language utterance caused individuals to become stressed as they constantly checked and rechecked language using digital translators. This use of electronic aid often hampered fluid conversations and negotiations within the university and its environs. Owaja and Rueda spoke of their "having to catch-up" with local peers because of their language abilities. Both were from China and studied English as their major at university there. They both expressed shock with the difference between the Englishes that they encountered in Canada when compared to the English previously learned in their home country. Rueda argued that she studied English for nine years in her home country yet she was subsequently still baffled with the English she encountered within the new social and academic communities. She thought there were gaps in the language she learned from the text, the language spoken among local groups, and the academic language she was expected to write and perform at the university. These thoughts were echoed by Owaja who self-proclaimed that he was a good English student back home yet in Canada he was constantly at odds with the language in his new context. Through their negotiations of these three registers of English, these participants were gaining valuable understandings of language registers and appropriate language use. They learned to distinguish appropriate and acceptable expressions used across the cultures that they engaged in daily. No one intentionally set out to teach them these utterances. These they were learning along the way through their interactions with their social and academic communities.

\section{STUDENT TO SCHOLAR: DISCUSSION}

Much like Lave and Wenger's (1991) theory, student to scholar describes how international graduate students learned and were able to move from novice students to expert scholars. This theory operates on the premise that newcomers, here international students who enter the new community of 
practice of the University or other post-secondary institutions, engage in activities from which they learn. Experiences that give light to the new ways are accessed through participation in the practices of the academic community, even if only on the periphery. Through their engagement students were able to continue inventing and reinventing themselves through improvisation and in their efforts to become successful scholars. It is through improvisation and the "trial and error" of approximation in acting, doing, participating and conferencing with other students and professors that learning occurs. Essentially, the sojourner student takes ownership for his or her learning, and negotiates the culturally relevant and appropriate behavior patterns, utterances, rhetoric and customs integral to building scholarship.

Notably, these "scholars-to-be" entered the university with varied knowledge and skills. Each was qualified for the level of study in which he or she was engaged, having studied previously at the tertiary level in his or her home country. They entered the university with the aim of becoming accomplished academics in their particular fields and gaining mastery that would allow them to act independently in their areas of study. The acquisition of master status positions students as scholars, rather than scholars to-be or scholars in waiting. The collected experiences suggested a constant interplay between being and becoming, as participants, through their stories, showed themselves as unique beings seeking to become a part of the university ethos. Aristotle (1994) argued that the term being usually presupposes the idea of becoming, which means that one has to be at a particular state before one can become another. Students constantly shift their roles as they "search for meaning and a negotiation of ethical behavior" (Suominen, 2005, p. 19) due to their outsider status and inherent lack of the requisite social, cultural, academic, and linguistic capital. The study revealed that participants became who they needed to be as a means of becoming scholars in the host community. The idea of change and becoming throughout this study implies that participants had to step out of their comfort zone to confront new and varied situations.

This engaged and situated learning became evident through participants' narratives. In the absence of a manual, participants engaged with members of the new academic community. Through a multilayered practice of observing, listening, speaking, reading and writing they were engaged in the emancipatory tool of self-praxis. As they learned to justify a response, to see other points of view, and engage in deeper levels of conversations, they were able to participate in profound discussions in classes. Their successful maneuvering of the norms of their home culture, the local provincial, and the academic cultures enabled them to accomplish desired academic goals and continue to succeed. By realizing and accepting 
their situation in the social world of the academy, they gained access to sources for understanding through a growing involvement within the social practice of the classroom community.

\section{Situated Practice}

Kim (1994) argued that for international students to become insiders they must participate in academic, cultural, and social activities in the new environment. This involvement allowed them access to the requisite knowledge, skills, sensitivities, and behaviors that needed to function as productive members of the group. Acquiring these skills becomes difficult because they are grounded in their home cultures and ethnic behaviors. The ethno-cultures from which these students come often hindered them from participating in the new culture (Mori, 2000). Participation often became restricted because these overseas students still operated under the rules of their home culture and were not ready to relinquish its hold on them (Shabatay, 1991).

Lave and Wenger (1991) argued that learning occurs through engagement in communities of practice. This means that students learn through acting and doing activities that are common to the community. The transition to graduate school requires the acquisition of new cultures, skills and competences. Unfortunately, students at the graduate level receive minimal formal training (Maxwell, 2006) regarding these expectations. This is further compounded by the fact that these individuals were already enculturated in their own cultural and ethnic behaviors and protocols. In lieu of formalized training sessions, participants were able to learn cultural and academic protocols through observing and completing everyday academic tasks, such as writing papers, presenting orally in class and conducting research, by themselves. Study results pointed to the observation, modeling and doing of everyday activities as a means by which individuals are able to learn and become knowledgeable and gain the cultural capital of the new community through assumed behaviors, customs and protocols.

In becoming scholars, in lieu of the required psychological tools, capital, participants found agency and praxis within themselves and initiated their own learning as they negotiated and interacted with their community and its local members. Praxis involves "critical reflection-and action upon-a situation of some degree shared by persons with common interests and common needs" (Greene, 1978, p. 100). This was an interesting finding since Maria realized that [she] was here by [herself] and "needed to find a way to deal with the issue." Concluding that she needed to address her situation, she took ownership of her own life and its trajectory as she participated in learning to strengthen and interweave strands of language, 
literacy, and content learning (Zwiers, 2008). These utterances were echoed in similar terms by Kuri, who, through her shared experiences, spoke of her engagement with and observation of her classmates and fellow students, living in the dorm in which she resided, then imitating their movements. By doing this participants were able to replicate and reinforce the acceptable behaviors of the community of practice.

Through observations and participation with the community, participants reported that their critical thinking skills had improved while taking courses that required critical analysis and intensive thinking and writing. Understandably, university courses require students to recognize, understand, and analyze in writing an argument read or presented to them. As students wrote on a subject matter and learned to analyze an argument, they discovered how arguments were constructed and became familiar with how experts in various disciplines thought and communicated. Hence, students gained access to intra-disciplinary concepts, subject-specific vocabulary, and fundamental issues around complex arguments. Indeed, this process exposed students to the sorts of higher-order thinking skills that prepared them to critique their world and formulate solutions to complex problems.

\section{Professor Mentoring}

Mentorship is a personal relationship that ensues between an individual who is experienced (mentor) and one who is less experienced (mentee or protégé) in particular areas. Dednick and Watson (2002) argued that it is a reciprocal relationship aimed at promoting development and growth. Such relationships notably bring about identity transformation. Participants in the study benefitted from relationships with professors and locally based students. These findings align with Lacina's (2002) argument that international students benefit from their relationships with professors in Lacina (2002) suggested that the relationship between professors and international students factors as an integral part of the experiences and possible success of these students in overseas universities. Friendships and connections with professors provided study participants the social and cultural capital needed to successfully maneuver within academic life as well as to bridge the gap to the outside world. Zhou, Jidal-Snape, Topping and Todman (2008) contended that overseas students benefit from interaction with host nationals socially, psychologically, culturally and academically. Furthermore, relationships with professors acted as a protective factor to their mental well-being of (Olivas \& Li, 2006). Through these social and dialogical interactions, participants were able to acquire the necessary social and cultural capital to flourish in the host university. Once 
these were mastered, students became more connected with the group and so their experiences in the new institution were enhanced.

In the case of this study, mentorship was a major factor that enhanced and assisted students in their learning. Having close relationships with faculty, staff and other students allowed participants to view their learning experiences as valuable and attainable.

\section{Triple Learning as Transactional Process}

Along the road, student to scholar participants negotiated a triple learning process in the community of practice. Triple learning is "a linguacultural and social phenomenon and provides valuable insight into how learning occurs among international graduate students studying in the university as a community of practice” (Palmer, 2015, p. 190). Triple learning is a unique transactional process of learning among three distinct languages and registers, as well as three cultures and subcultures of English: home, local provincial, and academic, within the learning community, the university. According to Dutro and Moran (2003), academic language proficiency is the ability to construct meaning from both oral and written language, relate complex ideas and information, recognize features of different genres, and use various linguistic strategies to communicate. In contrast, Diaz-Rico and Weed (2002) viewed academic language as a cognitive toolbox, a set of thinking skills and language abilities used to decode and encode complex concepts. The students' narratives demonstrated the interrelated transactional processes they experienced in adapting to their new registers.

Triple learning points to the holistic and ecological perspectives of learning and communication. Learning and operating necessitated the negotiations among these different registers and cultures as each played an important part in the learning process for participants. In the case of the Chinese students, they were often absorbed in translating local and academic language through hand-held digital translators and cellular phones. Participants with stronger English backgrounds were also attached to their own native dialects, which they maintained with their counterparts. Switching and translating from one register to the next points to the interconnectedness of the home, local community, and academic language in the process of learning. The three go hand in hand and must be properly negotiated. Once students were able to switch appropriately among the three, a paradigm shift occurred that resulted in transformations of their lives and perspectives, allowing learning to occur. 


\section{CONCLUSION AND RECOMMENDATION}

This paper highlights the learning experiences of international graduate students and expands the existing literature by providing a deeper understanding of their learning practices in overseas institutions, important to professors, international student managers and policy makers. This knowledge has the potential to inform pedagogy at the post-secondary level. Findings from this study also have implications for social learning theories and places language and culture as significant factors in the learning processes of these students as they negotiate and come to terms with the use of three varieties of language and culture.

Given the findings discussed, it is recommended that universities consider implementing mandatory inclusive intercultural training educational programs for faculty, staff, and students, including international students. This course could serve to acquaint all stakeholders within the university and communities of practice with the soft skills and knowledge important for working with the diverse body of students. Additionally, it would be useful for phenomenological studies to be conducted among a larger, more diverse group of international students at local, provincial, and national levels to replicate or articulate alternative experiences to the student-scholars highlighted in this study.

\section{REFERENCES}

Abel, C. F. (2002). Academic success and the international student: Research and recommendations. New Directions for Higher Education, 117, 13-20.

Aristotle. (1994). The Basic Works of Aristotle. Richard McKeon (Ed.). New York: Random House.

Association of Universities and Colleges of Canada [AUCC]. (2014). International Study. Retrieved from http://www.aucc.ca/policyissues/global-connections/international-study/

Association of Universities and Colleges of Canada [AUCC]. (2011). Trends in higher education. Ottawa, Canada. Retrieved from http://www.aucc.ca/wp-content/uploads /2011/05/trends-2011-vol1enrolment-e.pdf

Bamford, J. K. (2008). Improving international students' experiences of studying in the UK. Retrieved from http:://www.economicsnetwork.ac.uk/showcase/bramford

Bhandari, R. \& Blumenthal, P. (2011). Global student mobility and the twenty-first century silk road: National trends and new directions. In R. Bhandari \& P. Blumenthal (Eds.), International students and 
global mobility in higher education: National trends and new directions (pp. 1-23). New York, NY: Palgrave Macmillan.

Bourdieu, P. \& Passeron, J. C. (1990). Reproduction in education, society and culture. London: Sage Publications.

Bourdieu, P. (1986). The forms of capital. Bourdieu, P. (1986) In J. Richardson (Ed.), Handbook of Theory and Research for the Sociology of Education (pp. 241-258). New York: Greenwood.

Canadian Bureau for International Education, CBIE. (2014). Canada's performance in international education, 2012. Retrieved from http://www.cbie-bcei.ca/about-ie/facts-and-figures/

Canadian Bureau for International Education, CBIE. (2009). Canada first: The 2009 survey of international students. Retrieved from http://gostudy.ca/images/documents/download/ SurveyInternationalStudents_e.pdf

Choudaha, R. \& Chang, L. (2012). Trends in international student mobility: Research report 01. World Education Services. Retrieved from http://www.wes.org/ras/

Citizenship and Immigration Canada, (2014). Notice - New regulations for international students finalized. Retrieved from http://www.cic.gc.ca/english/department/media/

Citizenship and Immigration Canada. (2012). Preliminary tables:

Permanent and temporary residents, 2011. Retrieved from

http://www.cic.gc/english/resources/statistics/facts2011 /preliminary/06.asp

Cudmore, G. (2005). Globalization, internationalization and the recruitment of international students. Canadian Journal of Higher Education, 35 (1), 37-60.

Diaz-Rico, L. \& Weed, K. (2002). The cross cultural, language, and academic development handbook. A complete K-12 reference guide. Boston: Allyn \& Bacon.

Dutro, S. \& Moran, C. (2003). Rethinking English language instruction: An architectural approach. In G. Garcia. (Ed.), English learners: Reaching the highest level of literacy (pp.22-258). Newark, NJ: international Reading Association.

Egbo, B. (2008). Teaching for diversity in Canadian schools. Toronto: Pearson.

Fiske, S. T. \& Lee, T. L. (2012). Xenophobia and how to fight it: Immigrants as the quintessential other. In S. Wiley, G. Philogene and T. A. Revenson (Eds.), Social categories in everyday experience (pp. 151-164). Washington, D.C: APA. 
Florida, R. (2002). The rise of the creative class and how its transferring work, leisure, community and everyday life. New York, NY: Basic Books.

Freire, P. (2000). Pedagogy of the oppressed. New York: Continuum.

Fu, Q. (2013). Surviving as an international student: Chinese graduate students' participation in Canadian classrooms. (Masters Project Report). University of Saskatchewan. Unpublished Report.

Gadamer, H. (2004). Truth and method. London: Continuum International Publishing Group.

Gibbons, P. (2009). English learners, academic literacy, and thinking: Learning in the challenge zone. Portsmouth, NH: Heinmann.

Greene, M. (1978). Landscapes of learning. New York: TC Press.

Gunawardena, H. \& Wilson, R. (2012). International students at university: Understanding the student experience. Bern, Switzerland: Peter Lang.

Kim, Y. Y. (1994). Adapting to a new culture. In L. A. Samovar \& R. E. Porter (Eds.), Intercultural communication: A reader (7th ed.), (pp. 392-405). Belmont, California: Wadsworth Publishing Company.

Lacina, J. G. (2002). Preparing international students for a successful social experience in higher education. New Directions for Higher Education, 117, 21-27.

Lave, J. \& Wenger, E. (1991). Situated learning: Legitimate peripheral participation. New York: Cambridge University Press.

Leary, T. A. (2011). Supporting international students with first year transition into Canadian universities: Recommendations from Atlantic Canada (Doctoral dissertation). Retrieved from ProQuest Dissertations and Theses Database. (NR 83445)

Luzio-Lockett, A. (1998). The Squeezing Effect: The cross-cultural experience of international students. British Journal of Guidance and Counselling, 26(2), 209-223.

Madden-Dent, T. E. (2014). A phenomenological study of cultural transition and adjustment to Asian undergraduate international students using different cross-cultural treatments. ProQuest, UMI Dissertations Publishing.

Maguire, M. H. (2011). A missing dimension in multiculturalism in higher education: The marginalization of international students' voices and writing identities. Canadian Issues/Thèmes Canadiens, 35-40.

Mamiseishvili, K. (2011). International student persistence in US postsecondary institutions. Higher Education, 64, 1-17. DOI:10.1007/s10734-011-9477-0.

Margison, S. (2013). Equals or others?: Mobile students in a nationally bordered world. In S. Sovic \& M. Blythman (Eds.). International 
students negotiating higher education (pp. 9-27). London: Routledge.

Maxwell, J. A. (2006). Literature reviews of, and for educational research: Scholars before researchers. Educational Researcher, 35(9), 28-31.

McHale, P. (2011). Structural incentives to attract foreign students to Canada's postsecondary educational system: a comparative analysis. In R. Bhandari \& P. Blumenthal (Eds.), International students and global mobility in higher education: National trends and new directions (pp. 167-191). New York, NY: Palgrave Macmillan.

Monture-Angus, P. (1995). Thunder in my soul: A Mohawk woman speaks. Halifax, NS: Fernwood Publishing.

Morgan, M. (2012). The context of learning in higher education. In M. Morgan (Ed.). Improving the student experience: A practical guide for universities and colleges (pp.1-14). London: Routledge.

Mori, S. (2000). Addressing the mental health concerns of international students. Journal of Counselling and Development, 78(2), 137-144.

Olivas, M. \& Li, C. (2006). Understanding stressors of international students in higher education: What college counsellors and personnel need to know? Journal of Instructional Psychology, 33(3), 217-222.

Palmer, Y. (2015). Triple learning: The journey from student to scholar.

Retrieved from

http://ecommons.usask.ca/bitstream/handle/10388/ETD-2015-02-

1951/PALMER-DISSERTATION.pdf

Polkinghorne, D. E. (2005). Language and meaning: Data collection in qualitative research. Journal of Counselling Psychology, 52(2), 137145.

Popadiuk, N. \& Arthur, N. (2004). Counselling international students in Canadian schools. International Journal for the Advancement of Counselling, 26(2), 125- 145.

Rienties, B., Beausaert, S., Grohnert, T., Niemantsverdriet, S., \& Kommers, P. (2012). Understanding academic performance of international students: the role of ethnicity, academic and social integration. Higher Education, 63, 685-700.

Shabatay, V. (1991). The Stranger's story: Who calls and who answers? In C. Witherell \& N. Noddings (Eds.), Stories lives tell: Narrative and dialogue in Education (pp. 136-152). New York: Teachers College Press.

Sullivan, C. \& Kashubeck-West, S. (2015). The interplay of international students' acculturative stress, social support, and acculturation modes. Journal of International Students 5(1), 1-11. 
Suominen, A. (2005). Stranger within. The Journal of Social Theory in Art Education 25, 15-44. Available from ProQuest Education Journals.

Tannis, D. (2010). International students' lived experience seeking ICT assistance: Just click here. Available from ProQuest Dissertations and Theses Database.

Trans, L. (2013). Transformative learning and international students negotiating higher education. In S. Sovic \& M. Blythman (Eds.), International students negotiating higher education (pp. 124-141). London: Routledge.

Trice, A. G. (2003). Faculty perceptions of graduate international students: The benefits and challenges. Journal of studies in International Education 7, 379-403. DOI: 10.1177/102831503257120

van Manen, M. (1997). Researching lived experiences: Human Science for an action sensitive pedagogy (2nd ed.). Ontario, Canada: The Althouse Press.

Vygotsky, L. (1988). Thought and language. Alex Kozulin (Trans.). Cambridge, Massachusetts: The MIT Press.

Wenger, E. (1998). Communities of practice: Learning, meaning and identity. New York: Cambridge University Press.

Wenger, E. (2000). Communities of practice and social learning systems. Organization, 7(2), 225-246.

Zhang, X. (2011). Choices and challenges: Chinese graduate students' transitional issues at a Canadian University. Doctoral Dissertation. University of Saskatchewan.

Zhou, Y., Jindal-Snape, D., Topping, K., \& Todman, J. (2008). Theoretical models of culture shock and adaptation in international students in higher education. Studies in Higher Education, 33(1), 63-75.

Zhou, Y. (2012). Listening to voices: Understanding Chinese students' journey at a Canadian university. (Master's thesis), University of Saskatchewan, Saskatchewan, Canada. Available at ecommons.usask.ca.

Zwiers, J. (2014). Building academic language: Essential practices for content classrooms. San Francisco, CA: Jossey-Bass.

YOLANDA PALMER, PhD, is the Coordinator of Graduate Student Research in the College of Education at the University of Saskatchewan, Canada. Her areas of research include internationalization and higher education, transcultural academic literacies, multilingual and multicultural education, pedagogies of language, triple learning.

Email: yolanda.palmer@usask.ca 